\title{
Synoptic environment related to rapid cyclogenesis in the Eastern Mediterranean
}

\author{
K. Lagouvardos, V. Kotroni, and E. Defer \\ National Observatory of Athens, Institute of Environmental Research and Sustainable Development, Athens, Greece \\ Received: 22 November 2005 - Revised: 6 January 2006 - Accepted: 10 January 2006 - Published: 14 February 2006
}

\begin{abstract}
This paper presents first results on the investigation of the synoptic conditions that led to the rapid development of a low-pressure system over the Aegean Sea. Indeed, during the period 21-22 January 2004, a very deep cyclone was observed over the Aegean Sea with a minimum central pressure of $\sim 972 \mathrm{hPa}$, a value which is among the lowest observed over the entire Mediterranean Sea during the last 40 years. The rapid development was associated with a two-trough system that, under the influence of a very intense upper-level jet, was merged in one and then acquired a negative tilting. Additional information on the mesoscale organisation of the system is given, based on lightning data and space borne microwave and infrared observations.
\end{abstract}

\section{Introduction}

Explosive cyclogenesis is an interesting phenomenon worldwide, accompanied with high impact weather. The first climatological study on rapid cyclogenesis was performed by Sanders and Gyakum (1980). Later on various authors investigated the role of the synoptic environment as well as the role of surface features (e.g. surface fluxes) in the rapid deepening of cyclones (Gyakum and Danielson, 2000; Strahl and Smith, 2001; Martin and Otkin, 2004). In the frame of the present study, the 21-22 January 2004 case is investigated, which according to the MEDEX (MEDiterranean Experiment: medex.inm.uib.es) database was among the three deepest cyclones found in the entire Mediterranean during the last 40 years. Indeed, a low pressure record was set in eastern Aegean Sea with $972 \mathrm{hPa}$ at 12:00 UTC 22 January 2004 as measured by an automatic station in the area, while sustained winds in North Aegean islands exceeded $30 \mathrm{~ms}^{-1}$ with gusts up to $45 \mathrm{~ms}^{-1}$.

The study of the 21-22 January 2004 low-pressure system development is based on observations (including light-

Correspondence to: K. Lagouvardos

(lagouvar@meteo.noa.gr) ning measurements, infrared imagery and microwave satellite measurements) as well as on ECMWF analyses that permit to study the synoptic environment under which the lowpressure system was deepened so rapidly.

The rest of the paper is organised as follows: Sect. 2 is devoted to the synoptic description of the storm, while an insight into the microphysical characteristics of the storm is given in Sect. 3, based on microwave data from AQUA satellite. The last section presents the concluding remarks and prospects of this study.

\section{Synoptic description}

The very deep low which affected the Aegean sea was emanating from a low centre which on 12:00 UTC 21 January 2004 was located over Sidra Gulf, with $999 \mathrm{hPa}$ central pressure, associated with a cut-off low over Libya (not shown). The evolution of the cyclone during the next $24 \mathrm{~h}$ up to the time of its maximum deepening is documented through inspection of ECMWF analyses, showing mean sea level pressure, lightning activity (as recorded by the UK Met. Office Arrival Time Difference system (ATD hereafter) and upperair features (Figs. 1 and 2).

At 00:00 UTC 22 January the low pressure system has moved over the southern part of Continental Greece with a central pressure of $986 \mathrm{hPa}$ (Fig. 1a), $13 \mathrm{hPa}$ deeper than $12 \mathrm{~h}$ before. A two-trough system is evident over the Ionian Sea and the Sidra Gulf, while a very intense $300-\mathrm{hPa}$ jet is identified, with wind speed values up to $90 \mathrm{~ms}^{-1}$ just over the southern edge of the trough (Fig. 2a).

Significant vorticity advection is evident in the form of a band extending from the Gulf of Sidra towards the low centre, while a second but less pronounced band is evident over the northern Aegean Sea (green shaded contours in Fig. 1a). Lightning activity is observed over the low-pressure centre (red dots in Fig. 1a) as well as along the area of vorticity advection over the northern Aegean Sea. 


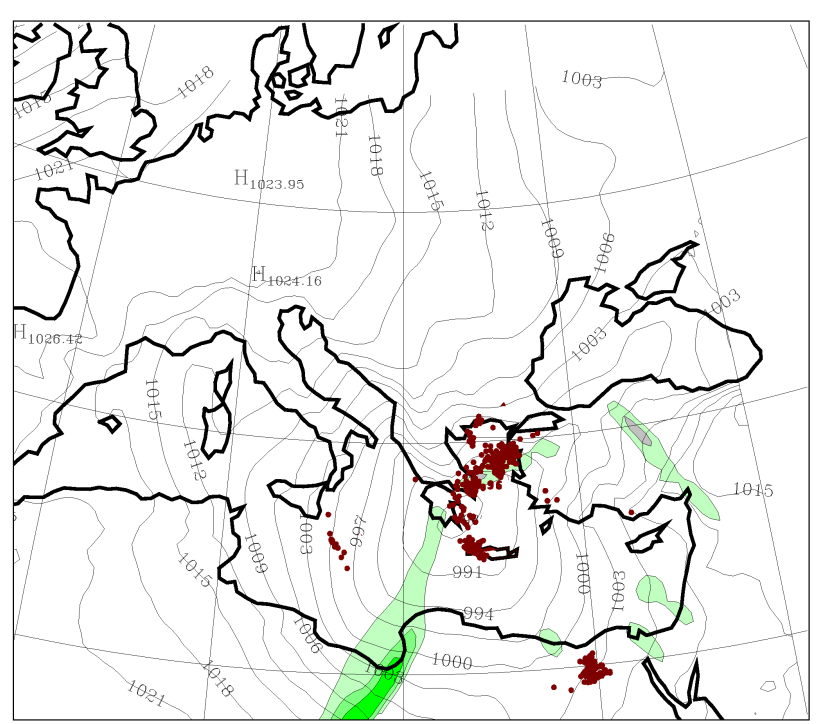

Fig. 1a. ECMWF analysis of mean-sea-level pressure (solid lines at $3 \mathrm{hPa}$ intervals) and of $500 \mathrm{hPa}$ absolute vorticity advection (green shaded contours at $2 \times 10^{-8} \mathrm{~s}^{-2}$ intervals) valid at 00:00 UTC 22 January 2004. Red dots denote the location of lightning flashes recorded by the UK Met. Office ATD system $\pm 30 \mathrm{~min}$ around the time of the image.

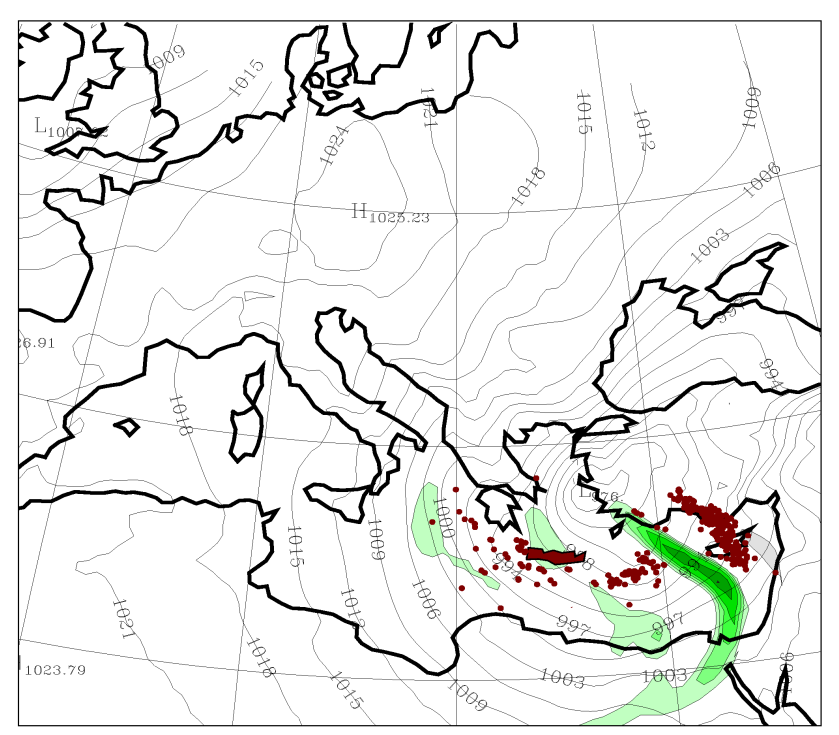

Fig. 1b. As in Fig. 1a, except at 12:00 UTC 22 January 2004.

During the following $12 \mathrm{~h}$, the low-pressure system moved northeastwards, rapidly deepening. At 12:00 UTC 22 January (Fig. 1b), the low-pressure system has reached its minimum pressure ( $976 \mathrm{hPa}$ over the eastern Aegean, as analysed by ECMWF, while a nearby automatic station recorded a low pressure of $972 \mathrm{hPa}$ at that time), $23 \mathrm{hPa}$ lower than the pressure value $24 \mathrm{~h}$ before.

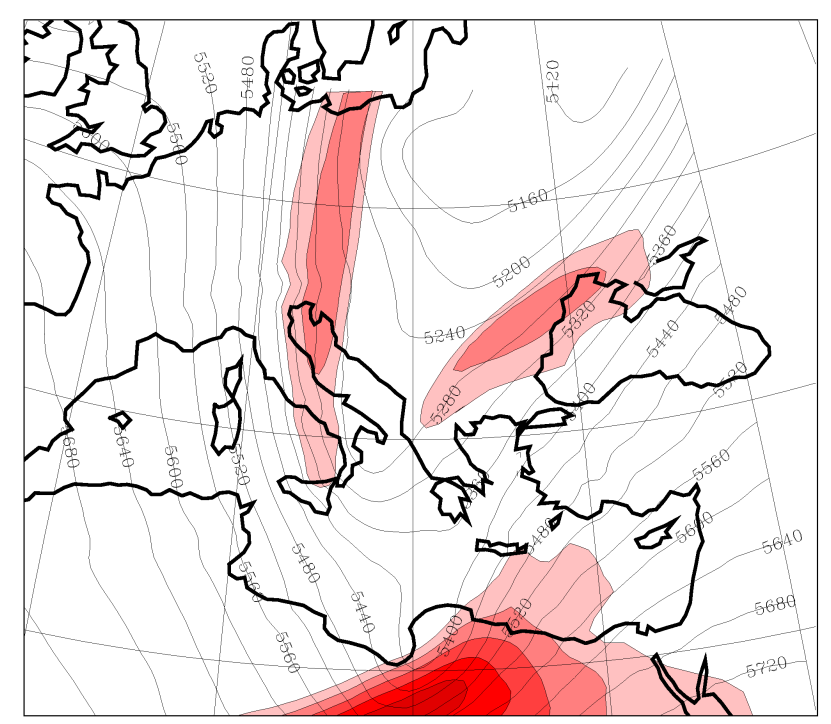

Fig. 2a. ECMWF analysis of $500 \mathrm{hPa}$ geopotential height (solid line at $60 \mathrm{~m}$ intervals) and of $300 \mathrm{hPa}$ wind speed (red shaded contours at $10 \mathrm{~ms}^{-1}$ intervals, only values greater than $50 \mathrm{~ms}^{-1}$ are shown) valid at 00:00 UTC 22 January 2004.

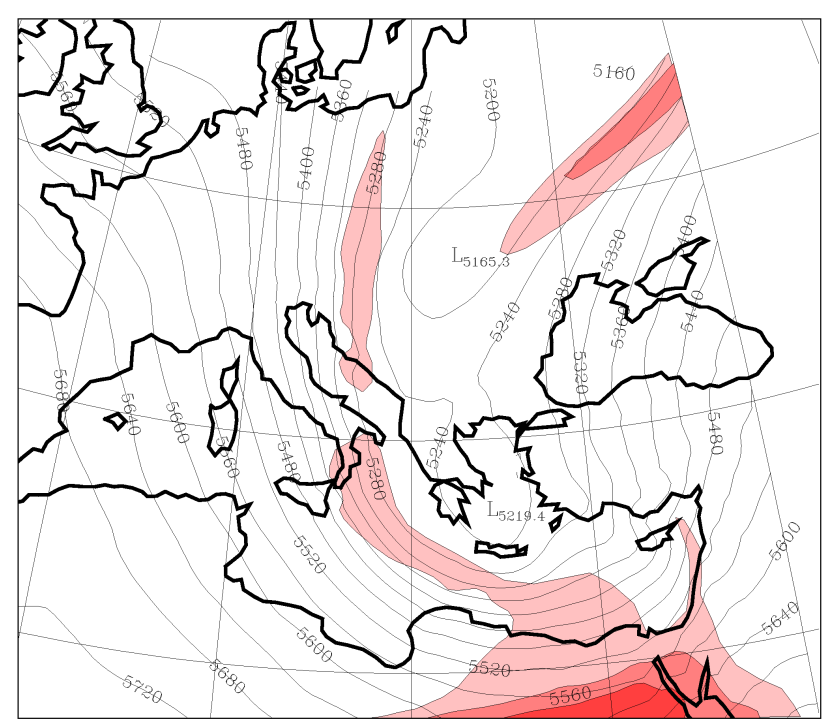

Fig. 2b. As in Fig. 2a, except at 00:00 UTC 22 January 2004.

Sanders and Gyakum (1980), have defined the formula of normalised deepening rate (NDR in bergeron units) for a cyclone:

$N D R=(\Delta p \times \sin 60) /(24 \mathrm{hPa} \times \sin \phi)$,

$\Delta p$ being the pressure fall in 24-h, and $\phi$ the latitude of the area. When this formula gives a value exceeding 1 bergeron, explosive cyclogenesis is taking place, and the cyclone can be caracterised as a "bomb". This formula gives for the latitude of the area over the Aegean $\left(\sim 36^{\circ} \mathrm{N}\right)$ and the observed 24-h central pressure fall of $\sim 23 \mathrm{hPa}$, a value of 1.4 bergeron and thus this event can be referred to as a "bomb". 


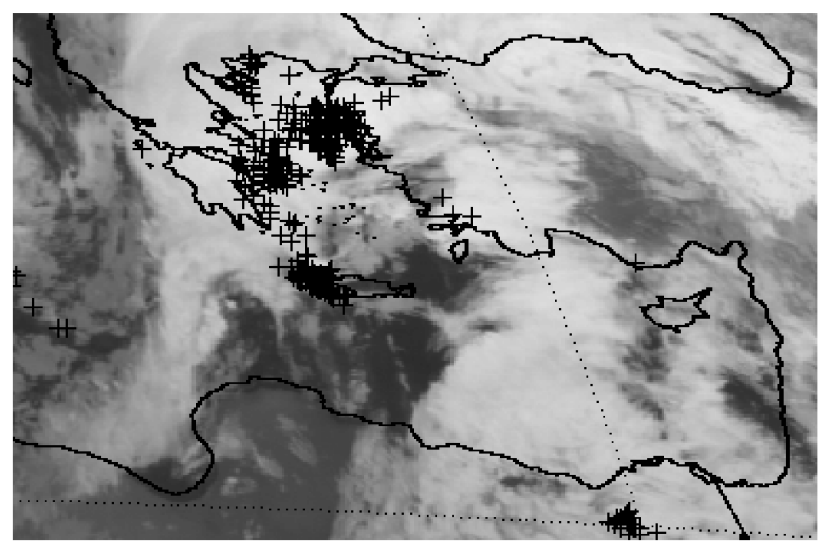

Fig. 3a. METEOSAT infrared image valid at 00:00 UTC 22 January 2004. Crosses denote the location of lightning flashes recorded by the UK Met. Office ATD system \pm 30 min around the time of the image.

Moreover, the vorticity advection maximum as well as the lightning activity have shifted over the eastern Mediterranean (green shaded contours in Fig. 1b), while scattered convection (as deduced from the presence of lightnings) is located in the western flank of the low-pressure system. At that time northern near surface winds over the Aegean Sea reached the maximum intensity, as discussed in the following. Looking at the upper-level features (Fig. 2b) during the last 12 hours important modifications have occurred: the two-trough system merged in one and became negatively tilted generating cyclonic vorticity. In this way vorticity advection is maximised within the merged trough, as indicated by the vorticity advection pattern shown in Fig. 1b.

METEOSAT infrared images at the same times (00:00 and 12:00 UTC 22 January 2004) with superposition of flashes location, are shown in Fig. 3. At 00:00 UTC (Fig. 3a) the lightning activity is scattered on the east of the low-pressure centre. Note also, a wide region of almost cloud-free conditions south of Crete, an indication of dry air masses that could be related to upper-tropospheric intrusion. Twelve hours later (Fig. 3b), lightning activity is organized in a line over the Cyprus area, as the trough line moves towards east (see Fig. 2b), while scattered flashes are observed on the western part of the system where METEOSAT imagery reveals the existence of scattered clouds.

Figure 4 shows the reports of the surface station network at 12:00 UTC 22 January 2004, the time when the deepening rate of the cyclone is maximum. At that time, the lowpressure centre was located over the eastern Aegean Sea, snowfall was reported over the Northern and Central part of Greece, as well as over the northern part of Athens area (as reported by station data). Northern sector winds prevailed all over the Aegean, with sustained winds between 27.5 and $30 \mathrm{~ms}^{-1}$ in some island stations over Southern Aegean. Wind gusts at Limnos and Skyros islands reached $45 \mathrm{~ms}^{-1}$. In both islands, significant destruction of electricity and telephone lines has been reported. Samos island reported a surface

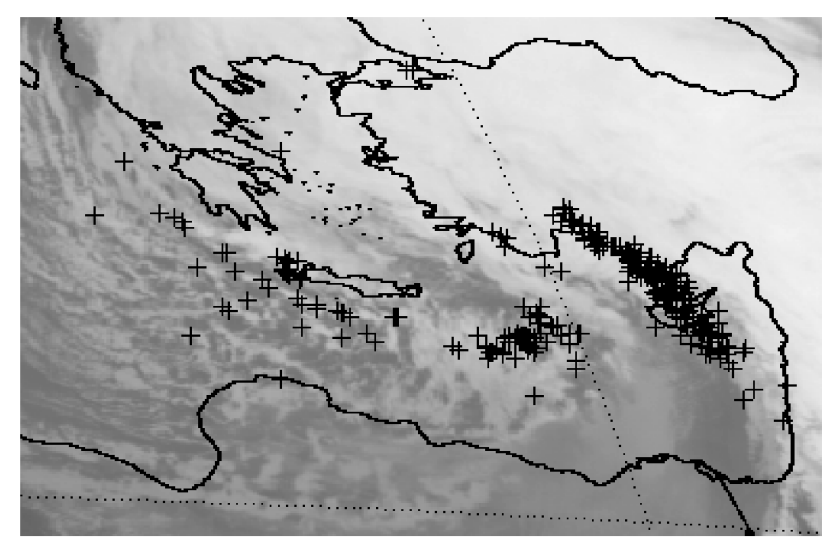

Fig. 3b. As in Fig. 3a, except at 12:00 UTC 22 January 2004.

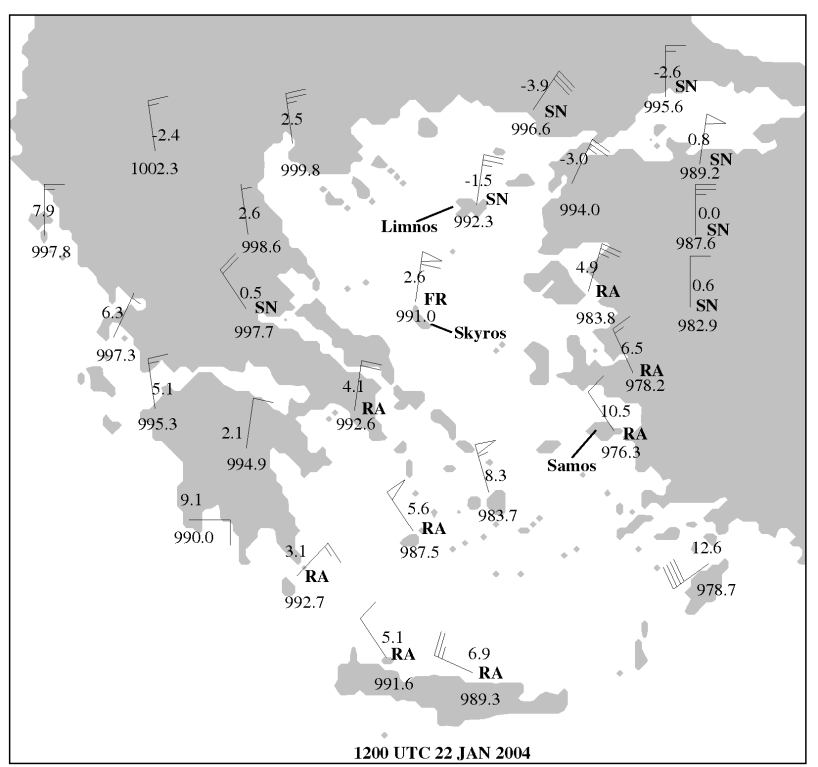

Fig. 4. Surface synoptic reports of temperature, mean sea level pressure and wind (one pennant: $25 \mathrm{~ms}^{-1}$, one barb: $5 \mathrm{~ms}^{-1}$, one halfbarb: $2.5 \mathrm{~ms}^{-1}$ ), valid at 12:00 UTC 22 January 2004. SN stands for snow, RA for rain and FR for freezing rain.

pressure of $976 \mathrm{hPa}$ (as analysed by ECMWF, see Fig. 1b), while in a small island $\sim 30 \mathrm{~km}$ to the west, the recorded pressure by an automatic station was $972 \mathrm{hPa}$.

\section{Microwave observations}

Passive microwave satellite observations are extensively used for the study of cloud properties. Microwave observations by the polar-orbiting AQUA satellite have been used in order to get some insight of the cloud properties of the studied system at 00:00 UTC 22 January when the low pressure centre was located approximately over the southeastern tip of Continental Greece. 


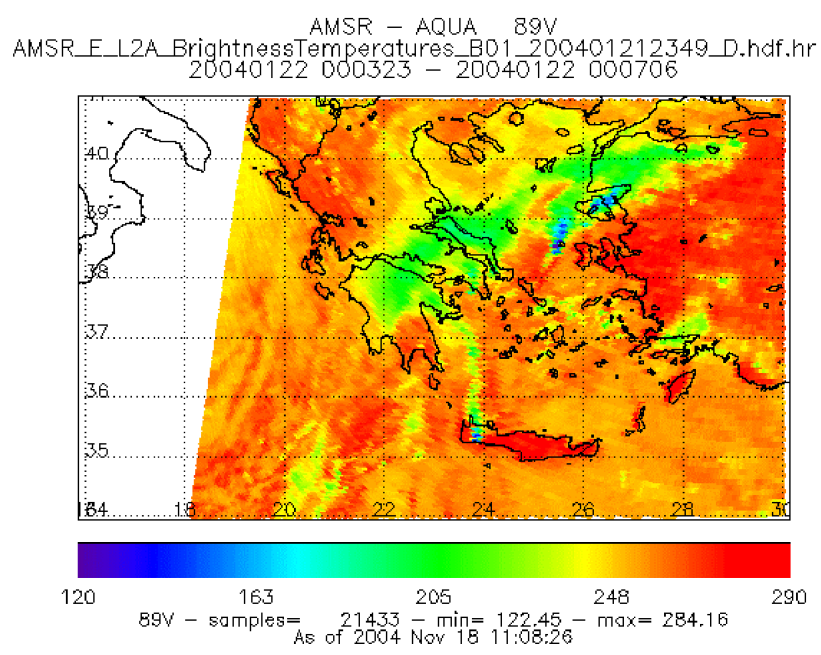

Fig. 5a. AQUA brightness temperature image at $89 \mathrm{GHz}$ vertical polarisation channel at 00:00 UTC 22 January 2004. Green and blue colours denote lower brightness temperature values.

The Advanced Microwave Scanning Radiometer for EOS (AMSR-E) is a twelve-channel, six-frequency, total power passive-microwave radiometer system, onboard AQUA satellite. It measures brightness temperatures at $6.925,10.65$, $18.7,23.8,36.5$, and $89.0 \mathrm{GHz}$. Vertically and horizontally polarized measurements are taken at all channels.

The overpass at 00:00 UTC 22 January over the area of interest is examined. Indeed, Fig. 5a presents AMSR-E brightness temperature at $89 \mathrm{GHz}$ vertical polarisation channel. This frequency is sensitive to the presence of ice and shows a thin line of low brightness temperature (green shading) over the maritime area north of Crete, just ahead from the low-pressure system. This cold signature, indicative of high concentration of ice is also associated with significant lightning activity (see Figs. 1a and 3a). Cold $89 \mathrm{GHz}$ brightness temperatures are also evident within the cloud mass over the central and northern part of the Aegean Sea and again this area is associated with significant lightning activity.

Figure $5 \mathrm{~b}$ shows the corresponding measurements at $36.5 \mathrm{GHz}$ horizontal polarisation that is sensitive to the presence of rain. Indeed, from the brightness temperature field the presence of rain can be deduced in a wide band in Northern and Central Aegean Sea, as well as in a narrow band ahead of the low pressure centre between mainland Greece and Crete.

\section{Concluding remarks-prospects}

The present paper aimed at presenting some initial results of the study of a Mediterranean "bomb" that reached a record low-pressure value $(\sim 972 \mathrm{hPa})$ over the Aegean Sea on 22 January 2004. This case of rapid cyclogenesis was associated with gale force winds that caused considerable damages over many islands of the Aegean Sea.

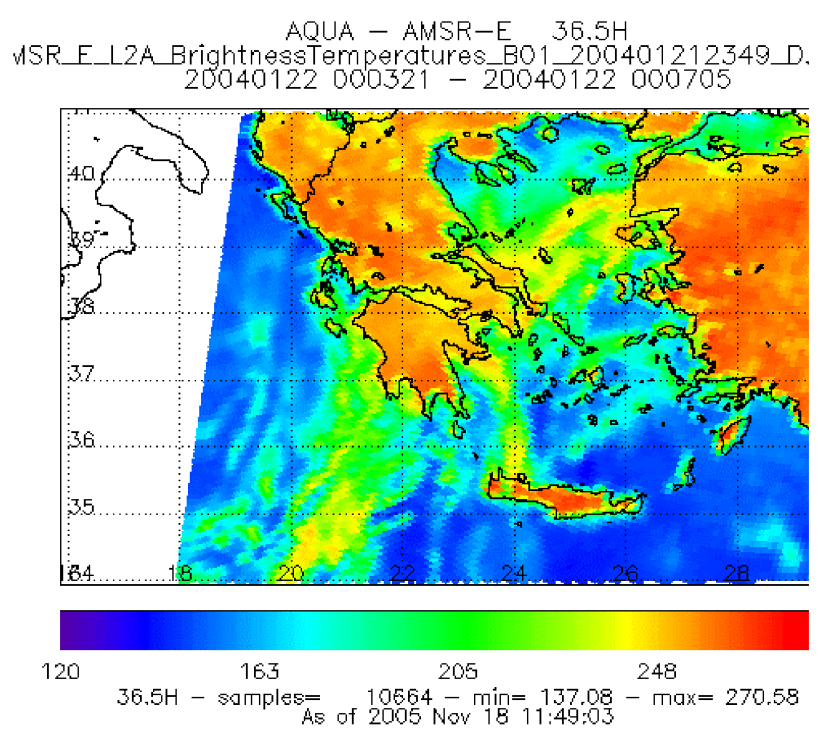

Fig. 5b. As in Fig. 5a, except at $36.5 \mathrm{GHz}$ horizontal polarisation channel.

The cyclone was studied through inspection of ECMWF analyses, lightning data and low orbiting satellite observations. The analysis showed that explosive cyclogenesis has taken place as the deepening rate of the cyclone was of the order of 1.4 bergerons. In the upper-levels, a two-trough system merged in one that become negatively tilted, producing in its turn considerable vorticity advection over the area of explosive cyclogenesis that leaded to the rapid development of the cyclone. Further, satellitte data gave indication of dry air masses that could be related to upper-tropospheric intrusion. Microwave observations helped to identify areas with low brightness temperature values at high frequencies, indicative of the presence of high ice concentrations that were well correlated with the presence of significant lightning activity in the same areas.

Additional work is required in order to get a better insight on the evolution of the system. For that reason, it is in the authors' immediate plans to identify the mechanisms that contributed to the rapid deepening of the system based on highresolution simulations with a limited area model.

Acknowledgements. This work has been jointly financed by the European Union (75\%) and the Greek Ministry of Development $(25 \%)$ in the framework of the program "Competitiveness Promotion of Excellence in Technological Development and Research - Excellence in Research Centers, Action 3.3.1", (MIS64563). The Hellenic National Meteorological Service is kindly acknowledged for providing surface stations data used in this study. NASA is acknowledged for AQUA data and EUMESAT for the METEOSAT infrared imagery. Finally, the UK Meteorological Office is acknowledged for the provision of data from the Arrival Time Difference (ATD) lightning detection system.

Edited by: L. Ferraris

Reviewed by: anonymous referee 


\section{References}

Gyakum, J. R and Danielson, R. E.: Analysis of meteorological precursors to ordinary and explosive cyclogenesis in the western north Pacific, Mon. Wea. Rev., 128, 851-863, 2000.

Martin, J. E and Otkin, J. A.: The rapid growth and decay of an extratropical cyclone over the central Pacific Ocean, Wea. Forecasting, 19, 358-376, 2004.
Sanders, F. and Gyakum, J. R.: Synoptic-dynamic climatology of the bomb, Mon. Wea. Rev., 108, 1589-1606, 1980.

Strahl, J. L. and Smith, P. J.: A diagnostic study of an explosively developing extratropical cyclone and an associated 500hPa trough merger, Mon. Wea. Rev., 129, 2310-2328, 2001. 